\title{
History of Mammography in Iran
}

\author{
Fariba Zarei ${ }^{1,2}$, Mahdi Saeedi-Moghadam ${ }^{1}$, Banafsheh Zeinali-Rafsanjani ${ }^{1,{ }^{*}}$ and Hannaneh Vahab \\ Aghaie $^{1}$
}

${ }^{1}$ Medical Imaging Research Center, Shiraz University of Medical Sciences, Shiraz, Iran

${ }^{2}$ Department of Radiology, Shiraz University of Medical Sciences, Shiraz, Iran

"Corresponding author: Medical Imaging Research Center, Shiraz University of Medical Sciences, Shiraz, Iran. Email: b.zeinali.r@gmail.com

Received 2020 July 06; Revised 2021 January 19; Accepted 2021 March 15.

Keywords: Mammography, History, Iran

\section{Dear editor,}

Mammography has a long and interesting history. It started with the curiosity of a German surgeon (Dr. Salomon, 1913) who attempted to visualize the tumoral tissue of a removed cancerous breast (1). Since then, significant advancements took place (2-4), and then 37 years later, Egan was the most fortunate one to win the honor of being the first person to make mammography universal. He developed a technique of mammography using an industrial film, a method that led to an outstanding result, which encouraged the radiologists to use it in the diagnosis of breast diseases (5). Along with mammography development, the mammography units also progressed from xeroradiography (6) to digital mammography units.

The development of mammography started from Berlin and continued in other Western countries. It evokes a question of how the situation in Eastern developing countries was and when they started to use these technologies. In this letter, we aimed to answer these questions for Iran, where there is a rich history of medicine.

\section{The history of breast diagnosis in Iran}

The oldest document of breast cancer diagnosis in Eastern countries goes back to $1600 \mathrm{BC}$. It is a handwritten text by the ancient Egyptians and describes the breast tumor as bulge masses in the breast with no cure. From Iran, Atousa, the great Cyrus's daughter was one of the first women who died at the age of 75 years old due to this cancer. According to the history books, an abscess appeared on her breast, which gradually started to spread. At first, it was small. She tried to hide her illness, but after a while that it got more se- rious, and then she asked her physician Democedes to cure her (7).

From this story, it can be understood that in those times breast cancer could not be diagnosed until it matured and appeared physically. Today, we know that in some cases such as inflammatory disease, 20 - 40\% of patients suffer from distant metastases in other parts of their body when the physical manifestations appear; therefore, diagnosis in this stage might be late for treatment (8).

Breast imaging technology made its way into Iran with 18 years of delay. A study entitled "Infrared thermography in Iran" was published in 1978 in the Journal of Acta Thermologica by Ghaem-Maghami. This document is the evidence of the fact that around 1978, thermography was used to diagnose the patient's disease (9). Unfortunately, the paper is inaccessible now since the journal had to be closed due to financial problems in 1984.

Infrared thermography is a method of sensing infrared energy emitted from the object, transforming it into temperature, and finally demonstrating the image of temperature distribution. It can transfer the heat via emission (directly from the surface of the body), convection (moving through gas or liquid), and conduction (transferring through solid). This imaging method had a wide use in breast imaging (10-12).

Based on the data collected from reliable sources, it was revealed that a general electric (GE) infrared thermograph, which worked with liquid nitrogen, was set up at Iran's Cancer Institute in around 1974 by Zohuri. Cancer Institute, located in the eastern part of Imam Khomeini 
Hospital (formerly Hezar Takhtekhabi Hospital and then Pahlavi Hospital), was established in 1955 . This cancer research center is one of the oldest research centers in Iran.

There is no more information about Dr. GhaemMaghami; according to the information gathered from his friends, he emigrated abroad in around 1979 - 1980. After him, Dr. Vahabaghaei (1933 - 2006) continued the job in his center. Dr. Vahabaghaei, who was living and studying in Germany, returned to Iran in 1977 to be with his countrymen during the conflicts due to the Islamic revolution, although at that time he was the vice-president of the radiology department of an important hospital in Bremen. He worked as an assistant professor with the Tehran University of Medical Sciences and also as the vice-chancellor of Financial Affairs of the university before joining the Dr. Ghaem-Maghami Center. He also worked in Amir Alam Hospital and as the head of the radiology department of the Women's Hospital, which was later renamed Mirza Koochak Khan Hospital.

Dr. Vahabaghaei studied the specialized courses of breast diseases in European countries and started his activity exclusively in the field of breast disease. He prepared the first brochure of breast self-examination, which was distributed for free among the patients referred to his center. He also developed and published the first atlas of mammography in Iran in collaboration with Dr. M. Hashemi and by collecting the mammograms, which were provided in Iran, and also shown on the cover page of this book.

The first X-ray mammogram methods were xeroradiography or xero-mammography. Xeroradiography does not require any dedicated X-ray tools; the difference between the two is only in the technique of recording an X-ray image. The recording process of the image can be done on a sensitive material such as selenium, which is a plate carrying an electrical charge on its surface. When the surface is irradiated with light, the charge is released. The plate is covered with a special powder, and the image is formed by the powder being attracted and retained in the charged area. Some of the xero-mammograms are extracted from the atlas of mammography (Figure 1).

According to engineer Zohuri, the first X-ray mammography equipment was set up at Shiraz Hospital (renamed Shahid Beheshti Hospital) and Isfahan Foroughi Abari Hospital in $1977-78$ at the beginning of their establishment

Although mammography arrived in Iran late, and it was not popular in the early years, many medical imaging centers today are equipped with these devices. For ex-

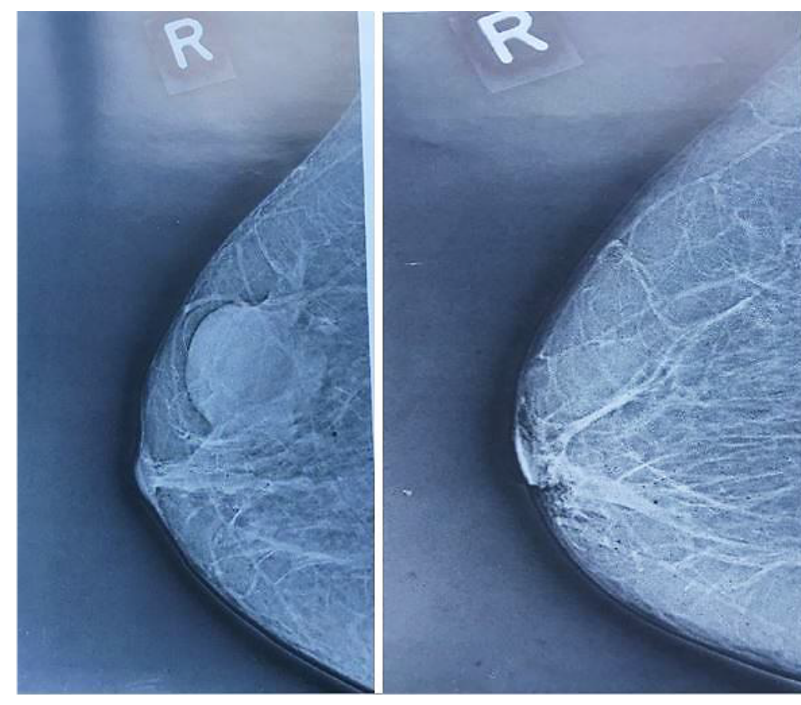

Figure 1. Xeromammograms provided in Iran (13).

ample, according to the Bureau of Radiology Affairs of Shiraz University of medical sciences, there are 25 mammography centers quipped with digital mammography facilities $[9$ centers with computed radiography (CR) mammography and 16 centers with digital radiography (DR) mammography]. In addition to Shiraz Hospital, 12 other cities of Fars province also offer facilities for digital mammography.

The increasing rate of studies based on mammography in Iran indexed in the PubMed database shows that mammography today is an interesting issue in clinic and research. Figure 2 shows the number of Iran-affiliated publications indexed in PubMed in the field of mammography between 2002 and 2019.

The topic of mammography screening was open for research from 1967 (14) until 19 years later when in 1986 the European Community (EC) proposed a pilot mammography screening program. Some of the European countries such as Germany started organized mammography screening from 2005 (15).

From 2010 to 2018, a total of 11 Iran-affiliated research papers indexed in PubMed were published on the topic of mammography screening (Figure 3); however, unfortunately, no systematic breast cancer screening plan using mammography was studied.

In this letter, we intend to express our gratitude to the first people who introduced and commissioned mammography devices in Iran. Despite the late arrival of mam- 


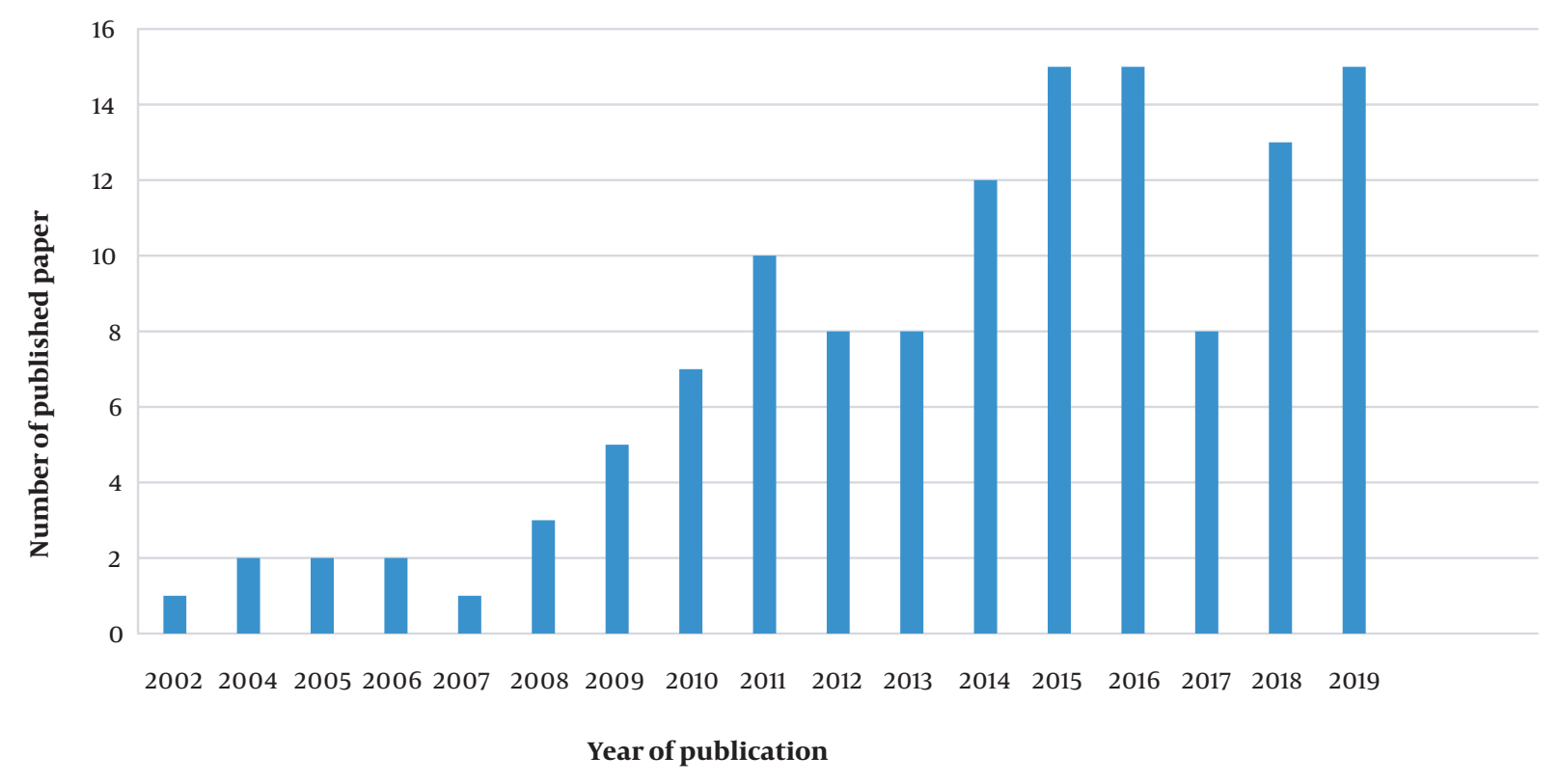

Figure 2. Number of Iran-affiliated publications indexed in PubMed in the field of mammography between 2002 and 2019.

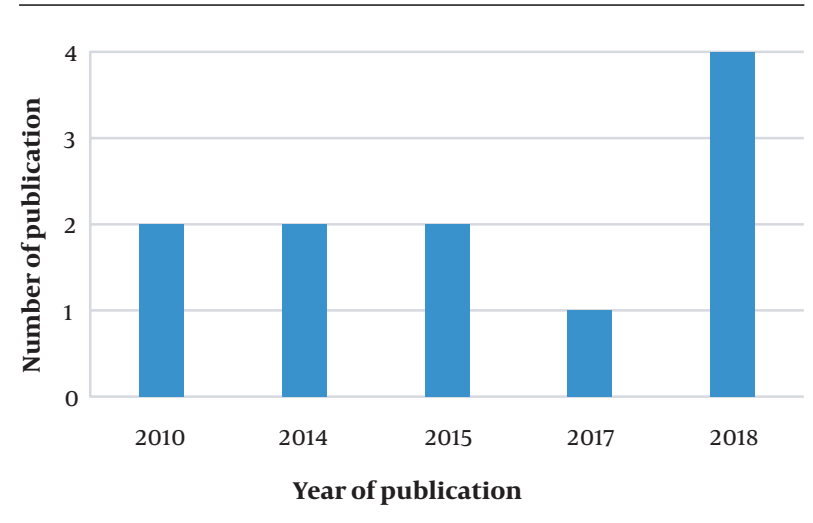

Figure 3. Number of Iran-affiliated publications indexed in PubMed in the field of mammography screening between 2010 and 2019 (there was no publication in the years that are not in the plot).

mography equipment to Iran, this method is completely accepted in the clinic and in almost all province centers equipped with facilities for digital mammography, and is also finding its way into future research works.

If readers have more information in this area, please contact the corresponding author.

\section{Footnotes}

Authors' Contribution: Main idea was from Fariba Zarei, Hannaneh Vahab Aghaie, and Banafsheh Zeinali-
Rafsanjani; Mahdi Saeedi-Moghadam gathered the information; Fariba Zarei and Mahdi Saeedi-Moghadam were involved in planning and supervising the work; and Banafsheh Zeinali-Rafsanjani drafted the manuscript and designed the figures. All authors discussed the results and commented on the manuscript.

Conflict of Interests: There is no conflict of interest.

Funding/Support: There was no funding support.

\section{References}

1. Kalaf JM. Mammography: A history of success and scientific enthusiasm. Radiol Bras. 2014;47(4):VII-VIII. doi: 10.1590/01003984.2014.47.4e2. [PubMed: 25741098]. [PubMed Central: PMC4337127].

2. Goldson. A. L. Cancer management in man: Detection, diagnosis, surgery, radiology, chronobiology, endocrine therapy. 1989th ed. Berlin, Germany: Springer; 2012.

3. Joe BN, Sickles EA. The evolution of breast imaging: Past to present. Radiology. 2014;273(2 Suppl):S23-44. doi: 10.1148/radiol.14141233. [PubMed: 25340437].

4. Gold RH, Bassett LW, Widoff BE. Highlights from the history of mammography. Radiographics. 1990;10(6):1111-31. doi: 10.1148/radiographics.10.6.2259767. [PubMed: 2259767].

5. Bassett LW, Mahoney MC, Apple S, D'Orsi C. Breast imaging expert radiologyseries e-book. Amsterdam, Netherlands: Elsevier Health Sciences; 2010.

6. Udoye $\mathrm{CI}$, Jafarzadeh $\mathrm{H}$. Xeroradiography: Stagnated after a promising beginning? A historical review. Eur J Dent. 2019;4(1):95-9. doi: 10.1055/s-0039-1697816. 
7. White FA. Physical signs in medicine and surgery: An atlas of rare, lost and forgotten physical signs : Includes a collection of extraordinary papers in medicine, surgery and the scientific method. London, United Kingdom: Museum Press; 2009.

8. Dawood S, Ueno NT, Valero V, Woodward WA, Buchholz TA, Hortobagyi $\mathrm{GN}$, et al. Identifying factors that impact survival among women with inflammatory breast cancer. Ann Oncol. 2012;23(4):870-5. doi: 10.1093/annonc/mdr319. [PubMed: 21765048].

9. Ghaem-Maghami P. Infrared thermography in Iran. Acta Thermographica. 1978;3:86-90.

10. Feasey CM, James WB, Davison M. A technique for breast thermography. Br J Radiol. 1970;43(511):462-5. doi: 10.1259/0007-1285-43-511-462. [PubMed: 5429085].

11. Gershon-Cohen J. Breast cancer: Roles of mammography and ther- mography. IMS Ind Med Surg. 1970;39(8):330-4. [PubMed: 5272585].

12. Gershon-Cohen J, Hermel MB, Murdock MG. Thermography in detection of early breast cancer. Cancer. 1970;26(5):1153-6. doi: 10.1002/1097-0142(197011)26:5<1153::aid-cncr2820260527>3.0.co;2-h. [PubMed: 5476795].

13. Hashemi M, Vahabaghaei H. [Atlas of mammography]. Tehran, Iran: Ketabe Mahnaz; 1995. Persian.

14. Nappi R, Niblio A, Vita G. Value of mammography and photophluorography in mass screening for breast cancer. $J$ Radiol Electrol Med Nucl.1967;48(11):664-5. [PubMed: 5591644].

15. Biesheuvel C, Weigel S, Heindel W. Mammography screening: Evidence, history and current practice in Germany and other european countries. Breast Care. 2011;6(2):104-9. doi: 10.1159/000327493. [PubMed: 21673820]. [PubMed Central: PMC3104900]. 